\title{
Tracheal stenosis due to relapsing polychondritis in rheumatoid arthritis
}

\author{
M E ROGERSON, E M HIGGINS, R C GODFREY \\ From the Department of Respiratory Medicine, Southampton General Hospital, Southampton
}

Upper airways disease is seen in $50-80 \%$ of necropsies in patients dying with rheumatoid arthritis. ${ }^{1}$ Most commonly the larynx is affected by synovitis of the cricoarytenoid joints, producing structural and functional changes with hoarseness, dyspnoea and sore throat. Submucosal granulomas in the postcricoid and subhyoid regions are associated with oedema and fibrosis producing substantial supraglottic narrowing. Non-rheumatoid conditions that may produce tracheal narrowing include tracheomalacia, the effects of endotracheal intubation, and sclerosing mediastinitis, which is usually associated with other mediastinal abnormalities.

We report a patient with longstanding rheumatoid arthritis whose tracheal stenosis was due to relapsing polychondritis.

\section{Case report}

A 41 year old woman with a 20 year history of seropositive rheumatoid arthritis was referred with a six month history of respiratory distress. She was dyspnoeic on minimal exertion with noisy respiration and had episodes of sputum retention and choking. Her rheumatoid disease was extensive, destructive, and complicated by Felty's syndrome and keratoconjunctivitis sicca. Multiple second and third line drugs and steroids had not fully controlled her disease and she was maintained on a small dose of prednisolone $(8 \mathrm{mg} /$ day).

One year before presentation she had complained of laryngeal tenderness in association with a generalised illness that was thought to be an acute episode of Felty's syndrome. There had never been any other evidence of cartilage inflammation or destruction.

On admission she showed extensive joint deformity. There was tachypnoea at rest and pronounced stridor. Pulmonary function tests showed an $\mathrm{FEV}_{1} / \mathrm{FVC}$ ratio of $0 \cdot 25 / 2 \cdot 19$ litres (predicted 2.54/2.951) and a maximal flow-volume loop consistent with upper airway obstruction. The chest radiograph was normal but laryngeal tomograms suggested a tracheal stricture $5 \mathrm{~cm}$ below the entrance to the larynx. Bronchoscopy showed localised stricture with normal tracheal mucosa, pharynx, and larynx. Acute respiratory distress followed the procedure and necessitated urgent resection of the tracheal stricture with end to end anastomosis. There was immediate relief of symptoms, but five days later she expectorated some sutures and on day 7 stridor recurred. Bronchoscopy then showed extensive tracheal narrowing with obvious mucosal oedema extending into the main bron-

Address for reprint requests: Dr M Rogerson, St Paul's Hospital, London WC2H 9AE.

Accepted. 23 February 1987 chi. She was treated immediately with intravenous methylprednisolone followed by high dose oral prednisolone.

Computed tomography of the thorax performed around the time of the second bronchoscopy showed tracheal narrowing from the origin of the superior vena cava to the proximal halves of the right and left main bronchi. The maximal transverse diameter at one level was $4 \mathrm{~mm}$ (fig 1 ).

Histology of the resected specimen showed loss of basophilia, an active inflammatory cell infiltrate, a severe degree of fibrosis invading the cartilage, and areas of new bone formation-all consistent with relapsing polychondritis (fig 2).

Her subsequent progress was marked by several episodes of stridor due to the formation of granulomatous tissue at the original resection site. These were managed initially by dilatation but became so frequent that a Montgomery tube was inserted to provide support and compression of the tracheal wall. Steroid dose reduction has been made possible by the addition of cyclosporin A $(6.25 \mathrm{mg} / \mathrm{kg} / \mathrm{day})$, with no adverse effects. Anticartilage matrix antibodies were absent and the erythrocyte sedimentation rate has been normal thoughout. Since the introduction of cyclosporin several other autoantibody titres (including rheumatoid factor) have fallen to undetectable levels. There has been no recurrence of stridor since the insertion of the Montgomery tube but results of pulmonary function tests have remained abnormal, possibly owing to the presence of the tube.

Aural and nasal cartilages remain normal but recurrent maxillary sinusitis may be related to the disease.

\section{Discussion}

Relapsing polycondritis is an uncommon condition of cartilage destruction, which is life threatening when it affects the trachea or aortic ring. ${ }^{2}$ Tracheal disease is the presenting feature in $10-15 \%$ of cases but more commonly there is

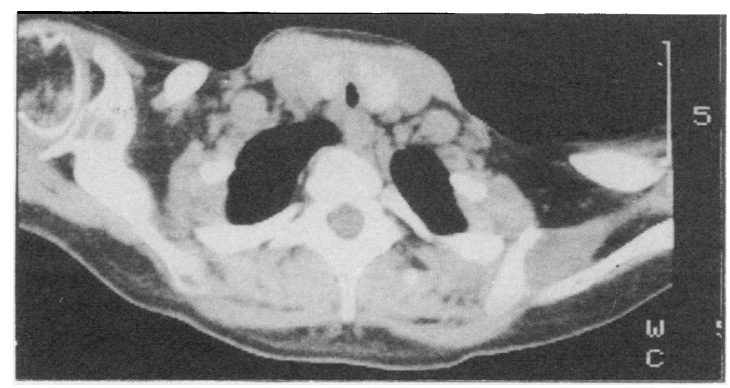

Fig 1 Computed tomography scan of thorax at the level of the apex of the lung showing substantial tracheal narrowing. 


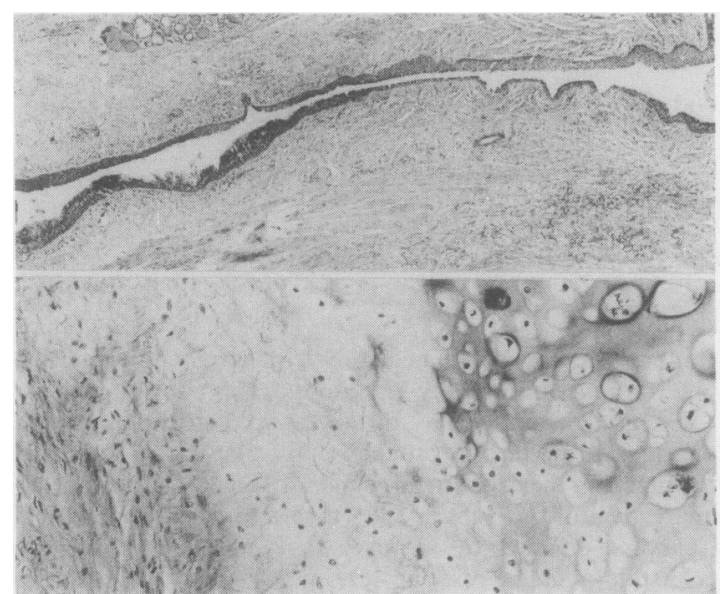

Fig 2 Top: Section of trachea encompassing almost the whole of the lumen. This has been reduced to a narrow slit. The tracheal mucosa shows extensive squamous metaplasia. (Masson's trichrome.)

Bottom: Tracheal cartilage. The cartilage to the right appears normal, in the centre it has undergone degeneration, and towards the left merges into fibrous tissue. (Masson's trichrome.)

pain, swelling and discoloration of the pinna or the nose. This characteristically remits but relapses and leads to cartilage destruction and collapse. Other areas affected are the Eustachian tubes, the costochondral joints, and the larynx. General features of fever, malaise, episcleritis, and polyarthropathy are common.

From $20 \%$ to $30 \%$ of cases are reported to be associated with conditions such as systemic lupus erythematosus, ulcerative colitis, rheumatoid arthritis, and thyroiditis which may have an autoimmune basis. ${ }^{34}$ Anticartilage antibodies (or antibodies to type II collagen) are found in two thirds of patients with relapsing polychondritis but in only $1.5 \%$ of patients with rheumatoid arthritis. ${ }^{3}$ One case of transmission of the disease in utero has been reported, ${ }^{4}$ suggesting an antibody mediated basis for this condition.

The primary histological abnormality in cartilage is loss of basophilic staining. This reflects loss of acid mucopolysaccharides that may be found in the urine. ${ }^{5}$ There is also acute chondritis followed by fibrosis and new bone formation, ${ }^{6}$ as seen in this patient. Surgical intervention has been reported to produce acute deterioration in other cartilage sites. 5
Steroids are the mainstay of treatment for all forms oQ relapsing polychondritis. In those cases affecting nose an£ ear alone the prognosis is good, but when the trachea on aorta is affected survival is much reduced. Other immus nosuppressive agents (for example, dapsone) have been trieg् in order to allow reduction in steroid dosage. Recently patient with extensive disease and with the larynx affecte was reported to respond dramatically to cyclosporin $A,{ }^{7}$ and. we are aware of another patient who showed a simila $\overrightarrow{\mathbb{E}_{0}}$ response to this new agent (M Walters, personal commus nication).

The incidence of relapsing polychondritis in rheumatoia arthritis is difficult to assess since reported numbers are small. An arthropathy very similar to rheumatoid arthritis i $\overrightarrow{\vec{n}}$ its distribution may also form part of the syndrome, makingo earlier reports difficult to assess. ${ }^{8}$ Polychondritis affecting the ears, eyes, and nose is reported in association with rheue matoid arthritis, ${ }^{9}$ but presentation with tracheal stenosis in this situation is to our knowledge unique.

We would like to thank Dr M Cawley for his advice an£ permission to report this case; Mr R Lea for expert assis tance; Professors D Wright and L Michaels for inter@ pretation of the histological specimens and Miss J Dennis for secretarial help.

\section{References}

1 Lanny G-V, Frierman ML, Hanafee WN, Mancuso AA. Laryn geal involvement in rheumatoid arthritis. A clinical, laryre goscopic and CT study. Arth Rheum 1984;27:873-82.

2 Hughes RAC, Berry CL, Siefert M, Lessof MH. Relapsing poly chondritis. Three cases with a clinico-pathological study and. literature review. $Q J$ Med 1972;41:363-80.

3 Ebringer R, Rook G, Swana GT, Bottazza GF, Doniach D. Aus toantibodies to cartilage and type II collagen in relapsing polychondritis and other rheumatic diseases. Ann Rheum Dis 1979;40:473-9.

4 Arundell FN, Haserick JR. Familial chronic atrophic poly chondritis. Arch Dermatol 1960;82:439-41.

5 Kaye RL, Sones DA. Relapsing polychondritis. Clinical and pas thological features in 14 cases. Ann Intern Mej 1964:60:653-64.

6 Verity MA, Larson WM, Madden SC. Relapsing polychondritiš. report of two necropsied cases with histochemical in vestigation of the cartilage lesion. $A m \quad J$ Patho 1963;42:251-69.

7 Svenson KGL, Holmdahl R, Klareskog L, et al. Cyclosporin treatment in a case of relapsing polychondritis. Scand Rheumatol 1984;13:329-33.

8 Thould AK, Stansfeld AG, Wykeham Balme H. Chronic atrov phic polychondritis. Ann Rheum Dis 1965;24:563-7.

9 Barth WF, Berson EL. Relapsing polychondritis, rheumatoid an thritis and blindness. Am J Ophthalmol 1968;66:890-6. 